\title{
FUNDAMENTOS PARA O DESENHO DE MECANISMO DE FOMENTO À LIQUIDEZ DO MERCADO SECUNDÁRIO DE ESPECTRO NO BRASIL
}

Foundations for the Design of Mechanisms to Fostering Liquidity in the Secondary Spectrum Market in Brazil

Submetido(submitted): 22/01/2020

Parecer(revised): 23/01/2020

Aceito(accepted): 30/01/2020

\author{
Luciano Charlita de Freitas* \\ Tiago Sousa Prado** \\ Agostinho L. de Souza Filho*** \\ Leonardo Euler de Moraes ${ }^{* * * *}$ \\ Ronaldo N. de Moura Filho ${ }^{* * * * *}$ \\ Juliano Stanzani* \\ Rafael Cavazzoni Lima******* \\ Luis Guilermo Alarcón López \\ Carlos Manuel Baigorri
}

\begin{abstract}
Purpose - The secondary spectrum market is an innovation within the Brazilian regulatory and legal framework introduced by the Law $n^{\circ} 13.879 / 2019$. Once in operation, it might allow allocative and productive efficiency gains for spectrum as well as to enhance competition in the provision of telecommunications services, particularly
\end{abstract}

*Especialista em Regulação e Doutor em Políticas de Desenvolvimento pela Universidade de Hiroshima, Japão. E-mail: lucianof@anatel.gov.br.

${ }^{* *}$ Especialista em Regulação e Doutorando em Informação e Mídia pela Michigan State University, Estados Unidos.

${ }^{* * * *}$ Especialista em Regulação e Doutor em Telecomunicações pela Universidade de Brasília, Brasil.

${ }^{* * * *}$ Especialista em Regulação e Mestre de Economia pela Universidade de Brasília, Brasil.

${ }^{* * * * *}$ Especialista em Regulação e Mestrando em Administração Pública pelo Instituto Brasiliense de Direito Público, Brasil.

******Especialista em Regulação e mestrando em Direito Econômico pela Universidade de Lisboa, Portugal.

${ }_{* * * * * * *}$ Especialista Sênior em Mercados Financeiros do Banco Interamericano de Desenvolvimento, Mestre em Finanças pela Universidade de Frankfurt, Alemanha, e em Direito Internacional pela Fletcher School of Law and Diplomacy, Estados Unidos.

${ }_{* * * * * * * *}$ Especialista Líder em Telecomunicações no Banco Interamericano de Desenvolvimento e Mestre em Administração de empresas (MBA) pela Escola de Comércio de Lyon, França.

**********E Especialista em Regulação e Doutor em Economia pela Universidade Católica de Brasília, Brasil.

FREITAS, L. C.; PRADO, T. S.; SOUZA FILHO, A. L. de; MORAES, L. E. de; MOURA FILHO, R. N. de; STANZANI, J.; LIMA, R. C.; LÓPEZ. L. G. A.; BAIGORRI, C. M. Fundamentos para Desenbo de Mecanismo de Fomento à Liquidez do Mercado Secundário de Espectro no Brasil. Revista de Direito, Estado e Telecomunicações, Brasília, v. 12, n 1, p. 187-204, Maio 2020. 
in regions with lower economic attractiveness. The objective of this study is to debate the foundations of the mechanism design to foster the secondary spectrum market liquidity in Brazil.

Methodology/approach/design - To this end, it is introduced three general mechanisms. The first deals with a laissez-faire approach without regulatory intervention. Then, a brokerage mechanism, widely used in the telecommunications wholesale market, and established on transparency instruments and cost oriented prices is discussed. Finally, a mechanism of License Shared Access with domestic meaningful incentives is assessed.

Findings - Results highlight the characteristics and shortcomings of each mechanism. The licensing-based mechanism with incentives displays a relative advantage over the other models.

Keywords: Secondary Spectrum Market. Mechanism Design. Incentives.

\section{Resumo}

Propósito - O mercado secundário de espectro é uma inovação regulatória no Brasil inaugurada pela Lei $\mathrm{n}^{\circ} 13.879 / 2019$. Uma vez em funcionamento, pode proporcionar ganhos de eficiência alocativa e produtiva e o aumento da competição na prestação de serviços de telecomunicações, com destaque para as regiões de menor atratividade econômica. $\mathrm{O}$ objetivo deste estudo é avaliar os fundamentos de mecanismos de fomento à liquidez no mercado secundário de espectro no Brasil.

Metodologia/abordagem/design - Para tanto é apresentado o desenho de três mecanismos gerais. O primeiro, do tipo laissez-faire, se refere a um arranjo de mercado sem intervenção do regulador. Em seguida, é discutido um mecanismo de corretagem, com amplo uso no mercado de atacado de telecomunicações brasileiro, e estabelecido sobre instrumentos de transparência e preços orientados a custos. Por fim, são feitas ponderações sobre uma solução de Acesso Compartilhado Autorizado (ACA) com incentivos.

Resultados - Os resultados destacam as características e limitações de cada mecanismo. O mecanismo baseado em cessão de autorização de uso de radiofrequências com incentivos demonstra vantagem relativa sobre os demais modelos.

Palavras-chave: Mercado Secundário de Espectro. Desenho de mecanismo. Incentivos.

\section{INTRODUÇÃO}

O mercado secundário de radiofrequências é uma inovação regulatória no Brasil inaugurada pela Lei $n^{\circ} 13.879 / 2019$ (BRASIL, 2019), que alterou a Lei $n^{\circ}$ 9.472/1997 - Lei Geral de Telecomunicações. A partir de então a legislação autorizou aos titulares do direito de uso de determinadas radiofrequências a possiblidade de transferi-la, comercializando parte ociosa do espectro, por exemplo, mediante anuência do regulador e submissão a condicionantes de natureza concorrencial.

FREITAS, L. C.; PRADO, T. S.; SOUZA FILHO, A. L. de; MORAES, L. E. de; MOURA FILHO, R. N. de; STANZANI, J.; LIMA, R. C.; LÓPEZ. L. G. A.; BAIGORRI, C. M. Fundamentos para Desenho de Mecanismo de Fomento à Liquidez do Mercado Secundário de Espectro no Brasil. Revista de Direito, Estado e Telecomunicações, Brasília, v. 12, nº 1, p. 187-204, Maio 2020.

DOI: https://doi.org/10.26512/lstr.v12i1.30005. 
A introdução das bases para esse novo mercado passa pelo reconhecimento de que há potencial para se lograr ganhos de eficiência e utilidade no uso de espectro a partir de configurações alternativas ao modelo tradicional, notadamente em regiões de menor atividade econômica. Tal constatação já havia sido explorada pelo regulador de comunicações norte americano no lançamento do debate sobre mercado secundário em 2000 (FCC, 2000). Na ocasião, constatou-se que a alegação de escassez de espectro decorria, em grande medida, da ineficiência de seu uso e não à escassez física.

Soluções de mercado secundário são usualmente associados a ganhos de eficiência alocativa e aumento da competição no setor de telecomunicações, em especial nos serviços móveis (OCDE, 2005). A principal vantagem de uma abordagem baseada na existência de um mercado secundário é a velocidade na designação do espectro, por permitir transações entre privados (LYONS, 2019). No domínio da tecnologia $5 \mathrm{G}$, cujo padrão de desenvolvimento se assenta em flexibilidade de rede, tais soluções podem contribuir para alavancar os negócios e ampliar o acesso ao consumidor final (FREYENS, 2009)

Trata-se, portanto, de cenário alternativo às soluções tradicionais de comando e controle estabelecidas sob o princípio da prevalência da exclusividade do uso das radiofrequências e, mais, da gestão concentrada em ator externo, no caso, o órgão regulador. $O$ novo modelo se justifica pelo reconhecimento de que a plena utilização de determinadas faixas de radiofrequências é influenciada por particularidades dos planos de negócios das prestadoras detentoras dessas autorizações de uso de radiofrequências, doravante referida como detentora de radiofrequências, a localização da prestação de serviço e a capacidade econômica do mercado. A introdução desse novo modelo de gestão do espectro permitirá, simultaneamente, a manutenção do uso corrente pelos titulares das radiofrequências e a cessão de parcelas ociosas para outros prestadores.

O presente estudo aborda três mecanismos alternativos para operacionalização do mercado secundário de espectro no Brasil. Assim, o (i) mecanismo do tipo laissez-faire, o (ii) modelo de brokerage, denominado para fins deste estudo com modelo de corretagem, com preços orientados a custos, e um (iii) mecanismo simplificado de Licenciamento de Acesso são analisados.

Especial ênfase é atribuída ao mecanismo de Licenciamento de Acesso. Esse destaque se deve às suas caraterísticas favoráveis à promoção da liquidez do mercado de espectro no Brasil. De modo a aperfeiçoar o modelo e adequá-lo ao cenário nacional, são propostas adaptações nos instrumentos de incentivos, concebidas à luz das práticas bem-sucedidas do regulador setorial no tocante à outorga de radiofrequências mediante leilão. 
O desenho desses mecanismos permite sistematizar a relação entre os atores envolvidos e, ao cabo, analisar soluções de mercado secundário que permitam equilibrar os interesses do titular das radiofrequências, potenciais cedentes desse recurso, e os potenciais cessionários.

A seção a seguir aborda as possibilidades e condicionamentos do mercado secundário de radiofrequências no Brasil à luz da recente aprovação legislativa. Em seguida, são debatidos os limites de soluções voluntárias para o mercado secundário de espectro e, por fim, são apresentados os mecanismos objeto deste estudo. A seção final resume os resultados do estudo.

\section{O MERCADO SECUNDÁRIO DE ESPECTRO NO CONTEXTO BRASILEIRO}

O mercado secundário foi introduzido no Brasil em 2019, na conjuntura da reforma do marco legal setorial. Nos termos da nova legislação ficou autorizada a cessão de uso de radiofrequências entre prestadores de serviços de telecomunicações, mediante anuência prévia da agência reguladora setorial.

$\mathrm{O}$ texto legal facultou a transferência do direito de uso de faixas de radiofrequências pelo titular original a terceiros. Ademais, outorgou ao regulador setorial as prerrogativas para regular esse mercado.

O papel do regulador, também explicitado na Lei $\mathrm{n}^{\circ} 13.879 / 2019$, inclui o estabelecimento de condições de preservação ou promoção da concorrência como condicionamento à eventual autorização de transferência de radiofrequências.

Dessa maneira, o negócio consiste na faculdade outorgada ao titular das radiofrequências para ceder a um terceiro, cessionário, o excedente ocioso de seu espectro, mediante contrapartida. As expectativas subscritas ao mercado secundário foram abordadas em decisões recentes da Agência Nacional de Telecomunicações (ANATEL, 2018a, 2019a). Dizem respeito à eficiência do uso de espectro, apontada como recurso habilitador para as atuais demandas da sociedade, e ao reconhecimento de que esse recurso é o meio preferencial para a conectividade no Brasil.

Iniciativas que culminaram na confirmação do mercado secundário convergem com o entendimento pregado por Coase (1959) de que o mercado tem condições de alocar recursos escassos de modo mais eficiente que a administração pública. Uma das razões é sua capacidade de processar informação de modo descentralizado, a partir de interações entre compradores e vendedores. Nessas condições, a adoção de uma solução de mercado tem a 
capacidade de tornar mais eficiente o uso do espectro em favor do atendimento às demandas da sociedade.

Essa modernização legislativa também se mostra afinada com referências internacionais sobre o tema. Experiências bem-sucedidas indicam o potencial do mercado secundário para agregar valor aos negócios de telecomunicações e na promoção da eficiência do uso do recurso (XAVIER e YPSILANTI, 2006). Outros relatos sugerem que incentivos podem potencializar a liquidez desse mercado e auxiliar na redução de custos operacionais e maiores retornos sobre investimento (DAOUDI, ALANYALI e STAROBINSKI, 2007).

$O$ regulador tem sob sua alçada a regulamentação desse mecanismo e se posiciona como guardião das boas práticas do mercado, devendo adotar medidas em prol da liquidez dessa modalidade de negócios e do uso mais eficiente de recursos escassos sob sua alçada. Essas atribuições abrangem iniciativas de defesa da competição, na harmonização dos interesses entre privados, fiscalização das condições impostas e arbitragem sobre divergências, quando necessário.

\section{MECANISMOS DE ESTÍMULO À LIQUIDEZ NO MERCADO SECUNDÁRIO DE ESPECTRO}

A demanda crescente nas últimas décadas por soluções de telecomunicações sem fio demonstrou a obsolescência da gestão do espectro de forma centralizada, por um regulador que atua em sistema de "comando e controle", no qual não há a possiblidade de transferência de autorizações por exemplo (SPILLER e CARDILLI, 1999). Nesse contexto, o desenvolvimento do mercado secundário de espectro deve ser, entre outros aspectos, uma resposta à dinâmica competitiva e de constante evolução tecnológica do setor de telecomunicações, às peculiaridades socioeconômicas e geográficas do país e à necessidade de renovação da política regulatória de promoção da eficiência do uso das radiofrequências. Para tal propósito, soluções de livre mercado e mecanismos mediados pelo regulador são alternativas que se apresentam.

Esta seção aborda algumas dessas soluções. De modo a sistematizar o problema, propõe-se o desenho de mecanismos com incentivos, estabelecidos sobre premissas de mitigação de riscos de conflitos e promoção de soluções de compartilhamento eficiente da radiofrequência. Um mecanismo ideal abrange incentivos para que, simultaneamente, os candidatos à aquisição do espectro revelem sua disposição para realizar avaliações verossímeis sobre o valor da radiofrequência desejada e, os titulares desse recurso para disponibilizá-lo no mercado secundário.

FREITAS, L. C.; PRADO, T. S.; SOUZA FILHO, A. L. de; MORAES, L. E. de; MOURA FILHO, R. N. de; STANZANI, J.; LIMA, R. C.; LÓPEZ. L. G. A.; BAIGORRI, C. M. Fundamentos para Desenho de Mecanismo de Fomento à Liquidez do Mercado Secundário de Espectro no Brasil. Revista de Direito, Estado e Telecomunicações, Brasília, v. 12, nº 1, p. 187-204, Maio 2020. 


\section{Business-as-Usual}

Até a edição da Lei $n^{\circ} 13.879 / 2019$, o modelo de outorga de radiofrequências brasileiro se estabelecia no direito intransferível de exploração desse recurso. Nesse formato, a autoridade regulatória se incumbia de segmentar blocos de espectro e sua posterior designação aos prestadores de serviços por meio de títulos de outorga, com prazos fixos, passíveis de prorrogação por uma única vez.

A competição nesse modelo se materializava nos leilões de radiofrequência cujas restrições eram, fundamentalmente, de ordem competitiva e sujeitas a limites máximos de concentração de frequências segundo o regime de spectrum cap (ANATEL, 2018b).

Nesse regime, as operadoras tradicionais participam dos leilões de espectro como precondição para sua permanência no mercado. Em regra, adquirem autorizações de uso de radiofrequências, em blocos regionais ou nacionais, de modo antecipado, prevendo necessidades futuras ou conforme suas estratégias de negócios (NERA, 2019). Os detentores do direito de uso do espectro eram titulares preferenciais das radiofrequências e não eram autorizados a comercializar o espectro, exceto em arranjos específicas como MVNO (ANATEL, 2010) e RAN SHARING (ANATEL, 2016). Adicionalmente a transferência do direito de uso seria possibilitado apenas com a transferência de toda a autorização.

O custo decorrente da aquisição do espectro nos leilões eleva o endividamento da prestadora que, por sua vez, o distribui no preço de varejo para os consumidores. Essas circunstâncias revelam uma condição de alocação sub-ótima de espectro, principalmente em termos geográficos, uma vez que o uso das radiofrequências é notoriamente reduzido, ou até mesmo inexistente, em regiões de baixa atratividade econômica.

Algumas desvantagens emblemáticas desse regime estão associadas ao padrão mais restritivo de concorrência e desincentivos à inovação (NERA, 2019). No tocante à concorrência, o modelo oferece poucas oportunidades para entrada de novos competidores em função dos prazos usualmente alongados entre as licitações.

Por sua vez, quanto à capacidade de inovação, prazos fixos e reduzidos impõem desincentivos a investimentos de longo prazo uma vez que a devolução do recurso não se compatibiliza com a expectativa temporal de retorno do investimento nesse setor.

Por essas, e outras razões, agências reguladoras de vários países passaram a questionar a efetividade do cenário business-as-usual e incentivar o desenvolvimento de mercados secundários. O regulador setorial dos Estados Unidos explicitou tal diagnóstico em um Policy Statement no qual reconhece

FREITAS, L. C.; PRADO, T. S.; SOUZA FILHO, A. L. de; MORAES, L. E. de; MOURA FILHO, R. N. de; STANZANI, J.; LIMA, R. C.; LÓPEZ. L. G. A.; BAIGORRI, C. M. Fundamentos para Desenho de Mecanismo de Fomento à Liquidez do Mercado Secundário de Espectro no Brasil. Revista de Direito, Estado e Telecomunicações, Brasília, v. 12, no 1, p. 187-204, Maio 2020.

DOI: https://doi.org/10.26512/1str.v12i1.30005. 
lastro do mercado secundário com o interesse público uma vez que esse mecanismo cria oportunidades para aumentar a capacidade de comunicação e a eficiência do uso do espectro (FCC, 2000).

Nessa visão, o mercado secundário complementa a função de designação das radiofrequências através de leilões e processos de autorização de uso de de espectro. Assim, embora o mercado secundário não deva suplantar o processo primário de disponibilização de espectro, credencia-se como mecanismo eficaz para suprimir sua escassez.

\section{Soluções de Mercado Secundário do Tipo Laissez-Faire}

Críticas às soluções business-as-usual se fundamentam na assimetria de informação e no conflito de interesses entre as partes envolvidas, com eventual prejuízo à consumação do mercado secundário de espectro. Estudo de Myerson e Satterthwaite (1983), cuja contribuição faz alusão ao teorema da impossibilidade de Arrow (ARROW, 1950), sustenta que na presença de assimetrias informacionais não haveria mecanismo que assegurasse eficiência ex-post na presença de racionalidade individual. Ao cabo, sugerem que a atuação regulatória permitiria, nessas circunstâncias, maximizar os potenciais ganhos de mecanismos comerciais.

Essas características intensificam as condições de assimetria uma vez que um comprador não conhece o custo do vendedor e este não conhece a disposição do comprador em pagar, de modo que são potencializados os riscos de ineficiência do comércio bilateral.

Assim, a despeito de ser a solução de mercado, em regra, preferencial, a experiência internacional demonstra que esse modelo é insuficiente para extrair todo o potencial do mercado secundário de espectro (OCDE, 2005). Isso ocorre porque, cada parte, agindo individualmente, tem incentivos para distorcer seu custo de venda, no caso do titular, ou a avaliação do valor do ativo, no caso do potencial cessionário, para obter um preço melhor. O vendedor poderia sobrestimar seu custo para obter maior retorno, enquanto o comprador teria como objetivo subestimar sua disposição de pagar de modo a obter um preço mais baixo. Assim, se deixados à própria sorte, as duas partes podem reduzir os potenciais de acordos.

Nessas circunstâncias a questão da eficiência do mercado permanece incerta. O equilíbrio do tipo Nash é posto em risco diante do ambiente geral de seleção adversa no qual informações e intenções ocultas ditam o comportamento dos agentes.

A teoria da agência dispõe de ume série de mecanismos gerais para a solução de problemas de agência. Com particular efeito sobre o presente estudo, se destaca os sistemas de compensação de incentivos (JENSEN e MECKLING,

FREITAS, L. C.; PRADO, T. S.; SOUZA FILHO, A. L. de; MORAES, L. E. de; MOURA FILHO, R. N. de; STANZANI, J.; LIMA, R. C.; LÓPEZ. L. G. A.; BAIGORRI, C. M. Fundamentos para Desenho de Mecanismo de Fomento à Liquidez do Mercado Secundário de Espectro no Brasil. Revista de Direito, Estado e Telecomunicações, Brasília, v. 12, nº 1, p. 187-204, Maio 2020.

DOI: https://doi.org/10.26512/1str.v12i1.30005. 
1976) ou sistemas de recompensa (EISENHARDT, 1989) segundo os quais a dimensão e importância atribuída aos incentivos são proporcionais à dificuldade de custo do monitoramento das atividades do agente. Os sistemas de compensação de incentivos combinam as preferências do agente com as do principal e visa oportunizar ganhos mútuos em prol de um equilíbrio desse sistema

A reação de autores face aos limites do modelo laissez-faire realça alguns dos elementos essenciais para que um sistema de mercado opere com eficiência (OCDE, 2005; FCC, 2000). Fazem referência específica à necessidade de se observar os direitos econômicos claramente definidos, informações sobre preços e disponibilidade de recursos e plataformas que permitam reunir compradores e vendedores para que, com um mínimo de custo transacional, operem em regime de competição que, em última instância, ditará o sucesso do negócio.

Cabe ressaltar que no regime de laissez-faire arranjos voluntários entre partes podem se materializar. Esse tipo de contrato, cujo propósito também se sustenta em requisitos de eficiência e custos. Acordos nesse domínio incluem a composição de faixas de radiofrequências adjacentes cujo agrupamento implica benefícios de cobertura e ampliação de base de clientes. Uma vez que não prejudique a competição, arranjos desse tipo podem estimular a eficiência agregada das empresas e maior qualidade do serviço.

Contudo, não se pode deixar de mencionar como ponto crítico desse modelo, vez que a prevenção e a solução de casos de interferência prejudicial de uso em radiofrequências, por sobreposição ou aproximação, exigem necessariamente um agente interveniente especializado. Spiller e Cardilli (1999) apontam não só a necessidade desse "árbitro", como da organização dos registros dos "títulos" das outorgas e das definições de seus limites.

\section{Modelo Brasileiro de Corretagem com Arbitragem (Brokerage)}

$\mathrm{O}$ mecanismo de corretagem espelha o arranjo adotado pelo regulador brasileiro de telecomunicações no âmbito do chamado Plano Geral de Metas de Competição- PGMC (ANATEL, 2018b). Consiste em um sistema unificado de transações de ofertas mandatórias de infraestrutura de atacado das empresas de telecomunicações com poder de mercado significativo, estabelecido sobre princípios de equidade e transparência. Os preços dos produtos são orientados a custos, estimados pelo regulador e estabelecidos em bases não discriminatórias a partir de dados de contabilidade regulatória.

O mecanismo de corretagem se distingue por sua simplicidade. Nesse modelo os preços são disponibilizados pelo regulador que também fica encarregado de arbitrar conflitos na comercialização desses produtos. A oferta mandatória de infraestrutura de atacado se resume aos prestadores com poder de 
mercado significativo. Nesses termos, o modelo dispensa a presença de incentivos econômicos para sua adesão.

A disposição de pagar dos compradores não seria revelada uma vez que o preço de oferta estabelecido ex ante pelo regulador suprime essa atribuição. Portanto, trata-se de um mecanismo que não incluiria entre seus preceitos a proposição de lances que expressem a real disposição para pagar, mas, apenas, uma análise de conveniência e oportunidade do comprador perante a eventual oferta disponibilizada de radiofrequências.

A modulação dos preços de referência pelo regulador é o principal vetor exógeno de demanda nesse modelo. $O$ fornecedor se compromete a disponibilizar recurso, mediante imposição regulamentar, no limite de sua disponibilidade. Nesse modelo existem fornecedores com oferta mandatória e candidatos compradores. Além das premissas gerais, o mecanismo se estrutura nos seguintes termos:

1. Existem $\mathrm{D}_{i}$ compradores com disposição de pagar $\mathrm{V}_{i}$ pelo uso das radiofrequências $\mathrm{I}_{i}$ em alternativa à construção de uma rede própria. Dado que j abrange diferentes características desse recurso, a exemplo da região de cobertura, da quantidade de $\mathrm{MHz}$ e a faixa de espectro disponibilizada.

2. D_i fará lance para aquisição do recurso caso o custo de construção por vias próprias $\mathrm{C}_{i}$ supere $\mathrm{V}_{i}$.

3. A oferta das radiofrequências $\mathrm{I}_{j}$ por seu titular $\mathrm{S}_{j}$ ocorre mediante postulação de pedido por Di e sua disponibilização se dá até o limite da capacidade excedente disponível de $\mathrm{I}_{j}$.

4. $\mathrm{O}$ detentor do recurso atribui um valor $\mathrm{V}_{j}$ para $\mathrm{I}_{j}$ pelo direito de uso em condições de exclusividade e de modo a cobrir o custo total de cessão do meio para um terceiro $\mathrm{C}_{m}$ cujos termos abrangem os custos operacionais de coordenação $\mathrm{C}_{c}$ e custo de oportunidade da disponibilização do meio $\mathrm{C}_{o}$.

5. $\mathrm{O}$ preço $\mathrm{P}_{i}$ é uma referência de custos definida pelo regulador e sobre ele pode incidir margens $\varepsilon$ para adequação a variáveis negociais como prazos, volume e localização. No modelo de brokerage o preço final de contratação do recurso corresponde a $\mathrm{P}_{i}+\varepsilon_{j}$.

$\mathrm{O}$ custo de cessão $\mathrm{C}_{m}$ é conhecido exclusivamente pelo titular das radiofrequências e a variável $\mathrm{C}_{c}$ compreende os custos subjacentes à cessão desse recurso. Abrange, por exemplo, custos de transação. Por sua vez, o custo de oportunidade $\mathrm{C}_{o}$ se refere aos ganhos que o titular poderia auferir, no 
momento atual ou futuro, com a exploração do recurso, e que não o faz por questões estratégicas ou competitivas.

No modelo de brokerage brasileiro o custo $\mathrm{C}_{s}$ é definido ex ante pelo regulador mediante modelos de custos. Para tanto, faz uso de dados da contabilidade regulatória e a adoção de premissas sobre a composição de custos fixos e variáveis de longo prazo (ANATEL, 2014).

O modelo dispensa os candidatos ao licenciamento da obrigação de revelarem o valor justo de oferta $\mathrm{V}_{i}$ e, ao titular, o compromisso de compartilhála sempre que for identificado como detentor de poder de mercado significativo. O aumento do retorno para o cedente do espectro é obtido quando:

[equação 1]

$$
\mathrm{V}_{j}<\mathrm{P}_{i}+\varepsilon_{j}
$$

Dado que $\mathrm{C}_{m}$ e $\mathrm{P}_{i}$ se equivalem no modelo de corretagem, os incentivos para o titular se engajar em um processo de cessão do recurso de modo voluntário se resumiria a $\varepsilon$. Por sua vez, a maximização do retorno para o cessionário seria do tipo:

[equação 2]

$$
\mathrm{C}_{i}>\mathrm{V}_{i}>\mathrm{P}_{i}+\varepsilon_{j}
$$

Nessas circunstâncias, a potencialização de seu retorno se materializa quando o valor a ser pago pelo recurso $\mathrm{P}_{i}+\varepsilon_{j}$ for inferior à sua predisposição oculta a pagar $\mathrm{V}_{i}$.

A despeito de inexistir um debate consolidado sobre o tema, a legislação delega ao regulador setorial a atribuição de fixar os valores de custos e dimensionar a variável $\varepsilon_{i}$ sempre que for acionado o recurso da arbitragem. Tal atuação se orienta à garantia de sustentabilidade desse mecanismo e na harmonização de interesses entre os titulares e os cessionários.

Em regra, trata-se de um custo transacional cuja justificativa reside na tentativa de mitigar abusos em mercados fundamentais de telecomunicações. A despeito de operar em conformidade com as expectativas do regulador, eventualmente, esse custo pode arrefecer os ganhos esperados do mecanismo de corretagem e impor riscos à credibilidade do modelo em mercados incipientes cuja estrutura de custos são incertas. 


\section{Acesso Compartilhado Autorizado com Incentivos}

O terceiro mecanismo identificado neste estudo se refere ao leilão de espectro no mercado secundário. Para fins de referência, adotou-se como modelo uma adaptação do Licenciamento de Acesso Compartilhado (ACA), cuja aplicação nesse novo mercado ganhou ímpeto a partir de 2011 (ECC, 2014). A adaptação se refere, primordialmente, ao caráter de cessão, temporária ou permanente, do espectro em substituição ao modelo de compartilhamento originalmente subscrito ao ACA.

Nos termos deste estudo, o arranjo é estabelecido a partir da cessão de acesso a faixas de radiofrequências sob titularidade de outro prestador. Aos moldes do modelo de corretagem, o ACA também abrange a atuação do titular do espectro, do cessionário e do regulador. Suas atribuições, todavia, se diferem do modelo anterior.

Neste caso, o cessionário precisa de uma autorização do regulador antes de acessar o espectro do titular. Essa licença abrange aspectos como as condições de compartilhamento, prazos e região geográfica de prestação de serviço e subscrição a determinadas condições de coordenação. O ACA garante ao titular do recurso e ao cessionário padrões de qualidade de serviço, especificado na licença.

O ACA se estabelece em duas fases. A primeira trata da alocação do espectro, mediante licitação e posterior designação do recurso ao titular. A segunda consiste em estabelecer um mecanismo eficiente para sua comercialização no mercado secundário, a exemplo de uma licitação do tipo Vickrey segundo a qual ofertas idôneas e sigilosas são apresentadas para uma única licença secundária e o pleito vencedor seria aquela de maior lance.

$\mathrm{O}$ modelo também se equipara à solução de corretagem quanto à disponibilização de repositório de informações sobre faixas de espectro ocioso e suas respectivas condições de cessão. Alguns termos fundamentais ditam a dinâmica do ACA no quadro de um mercado secundário de espectro:

1. O candidato à aquisição do espectro no mercado secundário é o que tem maior disposição a pagar $\mathrm{V}_{i}$ pela licença das radiofrequências.

2. $\mathrm{O}$ valor final do lance vencedor $\mathrm{V}_{a}$ é estabelecido em competição. No modelo de licitação do tipo Vickrey o preço de negociação $\mathrm{V}_{a}$ equivale ao segundo maior lance na licitação.

3. Por sua vez, o titular do espectro optará pelo compartilhamento sempre que $\mathrm{V}_{a}$ maximizar seu retorno, aos moldes no referido na seção anterior (equação 1).

FREITAS, L. C.; PRADO, T. S.; SOUZA FILHO, A. L. de; MORAES, L. E. de; MOURA FILHO, R. N. de; STANZANI, J.; LIMA, R. C.; LÓPEZ. L. G. A.; BAIGORRI, C. M. Fundamentos para Desenbo de Mecanismo de Fomento à Liquidez do Mercado Secundário de Espectro no Brasil. Revista de Direito, Estado e Telecomunicações, Brasília, v. 12, nº 1, p. 187-204, Maio 2020. 
4. Incentivos $E_{i}$ são disponibilizados pelo regulador a fim de reduzir o custo total de cessão do espectro $\mathrm{C}_{m}$. Por exemplo, os incentivos podem se manifestar na forma de descontos, isenções e subsídios.

A exemplo do modelo de corretagem, os ganhos do mercado são resumidos pelar soma dos ganhos do titular cedente do recurso $\mathrm{V}_{a}-\left(\mathrm{C}_{m}-\mathrm{E}_{i}\right)$ e do $\mathrm{V}_{a^{-}}\left(\mathrm{C}_{m}-\mathrm{E}_{i}\right)$. $\mathrm{O}$ regulador não intervém na definição de preços e os participantes do leilão são mais propensos a revelarem os valores reais $V_{i}$ e $V_{j}$ e, eventualmente, convergir para um valor justo de mercado. Por sua vez, o incentivo $\mathrm{E}_{i}$ opera como um amortecedor do custo de cessão do meio $\mathrm{C}_{m}$.

Experimentos com a definição de $\mathrm{E}_{i}$ em outros países indicam o emprego extensivo de abatimentos de taxas administrativas (MARSDEN e IHLE, 2018) ou a flexibilização da forma de adimplemento de metas de cobertura (FCC, 2019).

A identificação de incentivos adequados ao contexto nacional é essencial para o sucesso desse mecanismo. No Brasil, incentivos voltados à flexibilização do adimplemento das metas de cobertura, definidas no leilão primário de espectro, e que envolvem montantes expressivos de investimento e custo operacional parecem ter particular impacto (OCDE, 2016). Um exemplo de incentivo nesse escopo inclui a possibilidade de compartilhar essa obrigação entre o titular e o cessionário da radiofrequência. Nessas circunstâncias, os custos para atendimento da obrigação seriam segmentados entre dois ou mais prestadores ou, eventualmente, serviriam para contabilização das obrigações os investimentos correlatos realizados pelos cessionários.

Outro potencial incentivo com impacto para o ambiente doméstico diz respeito à eventual desoneração do ônus bienal pela prorrogação do uso das radiofrequências. Esse ônus, previsto em legislação, é devido pelo titular da radiofrequência após a prorrogação da outorga e incide usualmente sobre a receita operacional líquida auferida pela prestação do serviço e de maneira proporcional à quantidade de espectro prorrogada (ANATEL, 2018d). Adaptada a uma condição de incentivo, tal custo poderia ser compartilhado entre o titular e os cessionários ou mesmo reduzido a um patamar mais módico do que o praticado em condições de uso exclusivo do espectro.

Quando aplicável, o desenho do mecanismo de leilão deve observar, ainda, princípios de eficiência, transparência, a racionalidade individual dos participantes e a não discriminação de preços. Dado se tratar de problema complexo, com várias restrições, o eventual desbalanço entre esses princípios pode ser amortecido com um regime de compensação, usualmente atribuído aos instrumentos de incentivos. 
No tocante ao princípio da eficiência, consiste na soma das utilidades de todas as partes interessadas. Os excedentes do titular e do cessionário e o baixo custo transacional são componentes do ganho de bem-estar social e representam o valor geral da alocação. Nesses termos, um mecanismo é eficiente quando maximiza o bem-estar social.

A racionalidade individual assegura a competição no leilão, o que, por fim, potencializa seus ganhos. A estratégia individual dos participantes vislumbra ganhos de utilidade e sua soma representa maior eficiência ao sistema.

Combinado com a racionalidade existem dois princípios essenciais para o bom funcionamento do mecanismo. $O$ primeiro é o princípio da não discriminação de preços cujo objetivo é assegurar que os preços de um mesmo ativo são idênticos para os candidatos à sua aquisição. $O$ outro trata da não discriminação cuja importância se sustenta na livre participação de candidatos ao licenciamento, resguardadas as precondições de compliance regulatório estabelecidas pelo regulador setorial.

Nos termos postos, ressalvado o caráter introdutório do debate, o mecanismo de licitação atua sob a premissa de que todos os participantes do mercado secundário tenham retornos positivos. Trata-se de um modelo sustentado em incentivos e baixa intervenção que assegura retornos aos agentes envolvidos no mecanismo e ganhos de bem-estar social. Os sistemas de compensação de incentivo são soluções típicas para informações ocultas e ações ocultas.

\section{IMPLICAÇÕES SOBRE A REGULAÇÃO, O DIREITO DE USO E AS POLÍTICAS PÚBLICAS SETORIAIS}

A adoção do mercado secundário de espectro introduz no Brasil uma nova perspectiva sobre a gestão e o direito de uso de espectro. Seus efeitos abrangem benefícios econômicos associados à maior competição e eficiência no uso do espectro, entre outros.

Nesse cenário, prestadores de serviços podem se beneficiar do mercado secundário. Em particular, prestadores regionais ou locais, que já atuam com êxito nas regiões com menor atratividade econômica (CGI.br, 2018) de modo individual ou em consórcios podem promover maior dinâmica na oferta de serviços sobre espectro no interior do país e elevar, desse modo, a eficiência do uso do espectro nessas regiões.

Para que esse novo mercado seja efetivo e promova a liquidez esperada, as autoridades reguladoras devem promover arranjos de espectro que propiciem

FREITAS, L. C.; PRADO, T. S.; SOUZA FILHO, A. L. de; MORAES, L. E. de; MOURA FILHO, R. N. de; STANZANI, J.; LIMA, R. C.; LÓPEZ. L. G. A.; BAIGORRI, C. M. Fundamentos para Desenho de Mecanismo de Fomento à Liquidez do Mercado Secundário de Espectro no Brasil. Revista de Direito, Estado e Telecomunicações, Brasília, v. 12, nº 1, p. 187-204, Maio 2020.

DOI: https://doi.org/10.26512/lstr.v12i1.30005. 
o desenvolvimento desse mercado. Em adição, aprimoramentos dos métodos de gerenciamento das diferentes características de uso do espectro devem ser desenvolvidos de modo a assegurar a sincronização das modalidades de serviços e tecnologias empregadas. Incluem-se nesse escopo a alocação de meios para criação de plataformas digitais de espectro, o fortalecimento dos órgãos de acompanhamento do uso de espectro, a garantia de concorrência e de resolução de conflitos e arbitragem.

Do ponto de vista da legalidade do novo mercado, cabe um debate qualificado sobre o direito de uso e transferência desse direito entre entes privados. Abrange o debate sobre a possibilidade de arrendamento com prazo fixo e uma redefinição abrangente sobre os conceitos de divisão e combinação de espectro por região, tempo e faixas de radiofrequências.

Todos os aspectos do mercado secundário de espectro estão sujeitos a uma compreensão plena sobre o direito de uso desse recurso. Assim o modo, a duração, a abrangência e a flexibilidade dos contratos abrangem o intercâmbio de titularidade da licença, seu compartilhamento, agregação ou sua troca.

Nessas circunstâncias, o direito de uso resultante de arranjos do mercado secundário pode ser estabelecido sobre bases geográficas, duração e submissão a termos de proteção de interferência e de governança. $\mathrm{O}$ direito de uso por um período limitado ou sujeito a múltiplas prorrogações não impedem a retomada dos recursos pela autoridade pública em função de falhas de mercado ou com base em políticas públicas, ou ainda tendo em vista seu eventual mau uso. Essa condição reforça os limites do direito de sua exploração e o caráter precário de seu uso.

\section{CONCLUSÃO}

O desenvolvimento de modernos serviços de telecomunicações, possibilitado por transformações tecnológicas, convergência e mudanças de hábitos de consumo impõem uma crescente demanda por espectro. $\mathrm{O}$ mercado secundário de espectro oportuniza ganhos de eficiência no uso e na alocação mais sustentável desse insumo.

Este estudo apresentou mecanismos alternativos de promoção da liquidez no mercado secundário de espectro no Brasil. Ênfase foi atribuída ao cenário brasileiro e as idiossincrasias que afetam a forma como o mercado se organiza. Tratou-se, igualmente, de incentivos necessários para assegurar liquidez nesse mercado.

Por ser um debate de caráter introdutório, este estudo foi formulado sobre bases hipotéticas, inspirado por experiências internacionais e revisão 
bibliográfica sobre o tema. Uma revisão da literatura sobre direito de uso e sua transferência entre terceiros introduz elementos jurídicos ao debate, pouco exploradas na literatura especializada brasileira.

Quanto aos benefícios do mercado secundário, sobretudo para a conectividade de regiões carentes de serviços e infraestrutura, espera-se que uma maior eficiência na alocação desse recuso e a liberdade para os titulares de comercializarem espectro induzirão um uso mais intensivo e eficiente desse recurso escasso e essencial para o desenvolvimento do Brasil.

Essa característica revela um locus particularmente favorável aos provedores de serviços regionais, cujo desempenho tem mostrado particular desenvoltura em regiões com menor atividade econômica relativa.

Para os operadores tradicionais, titulares do recurso, a opção de transferência de direito de uso ou arrendamento de capacidade espectral ociosa também representa uma oportunidade de negócio. Entende-se que, ao ceder sua capacidade ociosa, esses prestadores podem tornar mais eficientes sua operação e menores os custos decorrentes da retenção desse recurso.

O mecanismo de licitação de radiofrequências com incentivos no mercado secundário é apontado como o que oferece maior potencial para o uso eficiente do recurso e o que mais potencializa seus benefícios. Para ser efetivo requer uma abordagem regulatória, ainda que reduzida, notadamente nos temas de competição e definição de incentivos.

O modelo de licitação também se mostra compatível com a atual política de mínima intervenção regulatória. Nas circunstâncias postas, o valor final da precificação das radiofrequências ocorreria sobre bases competitivas e os incentivos alinhados com as melhores práticas de responsividade em debate no setor (ANATEL, 2018e). Nessa mesma linha, o mecanismo tem o potencial de favorecer a implantação de novas tecnologias, produtos e serviços em benefício da sociedade e, desse modo, ao agregar valor às radiofrequências disponíveis para a sociedade brasileira.

\title{
REFERÊNCIAS BIBLIOGRÁFICAS
}

\author{
AGÊNCIA NACIONAL DE TELECOMUNICAÇÕES - ANATEL. Resolução \\ $n^{\circ}$ 550, de 22 de novembro de 2010: Regulamento sobre Exploração \\ de Serviço Móvel Pessoal - SMP por meio de Rede Virtual (RRV- \\ SMP). Brasília: ANATEL, 2010.
}

FREITAS, L. C.; PRADO, T. S.; SOUZA FILHO, A. L. de; MORAES, L. E. de; MOURA FILHO, R. N. de; STANZANI, J.; LIMA, R. C.; LÓPEZ. L. G. A.; BAIGORRI, C. M. Fundamentos para Desenho de Mecanismo de Fomento à Liquidez do Mercado Secundário de Espectro no Brasil. Revista de Direito, Estado e Telecomunicações, Brasília, v. 12, n 1, p. 187-204, Maio 2020. 
Resolução $\mathrm{n}^{0}$ 671, de 3 de novembro de 2016: Regulamento de Uso do Espectro de Radiofrequências e altera o Regulamento de Cobrança de Preço Público pelo Direito de Uso de Radiofrequências e o Regulamento de Aplicação de Sanções Administrativas. Brasília: ANATEL, 2016.

Processo $n^{0}$ 53500.014958/2016-89: Projeto Estratégico de Reavaliação do Modelo de Gestão do Espectro. Brasília: ANATEL, 2018a.

. Resolução $\mathbf{n}^{0}$ 703, de 01 de novembro de 2018: Estabelece Limites Máximos de Quantidade de Espectro de Radiofrequências. Brasília: ANATEL, 2018b.

. Resolução no 694, de 17 de julho de 2018: Altera o Plano Geral de Metas de Competição - PGMC. Brasília: ANATEL, 2018c.

- Resolução no 695, de 20 de julho de 2018: Regulamento de Cobrança de Preço Público pelo Direito de Uso de Radiofrequências. Brasília: ANATEL, 2018d.

Consulta Pública $n^{0}$ 53/2018: Regulamento de Fiscalização Regulatória. Brasília: ANATEL, 2018e.

Processo $\mathrm{n}^{\mathrm{o}}$ 53500.025122/2014-48: Adimplemento de compromissos de abrangência previstos no Edital de Licitação $\mathbf{n}^{0}$ 004/2012/PVCP/SPV-Anatel. Brasília: ANATEL, 2019a.

ARROW, K.J. A difficulty in the concept of social welfare. Journal of Political Economy, 58, p. 328-346, 1950.

BRASIL. Lei $n^{0}$ 13.879, de 3 de outubro de 2019: Altera a Lei ${ }^{\circ}$ 9.472, de 16 de julho de 1997, para permitir a adaptação da modalidade de outorga de serviço de telecomunicações de concessão para autorização, e a Lei $\mathrm{n}^{0}$ 9.998, de 17 de agosto de 2000, e revoga dispositivos da Lei $\mathbf{n}^{\circ}$ 9.472, de 16 de julho de 1997. Brasília: Presidência da República, 2019.

COASE, R. The Federal Communications Commission. Journal of Political Economy, II (2) J. Law. \& Econ, v. 1, 1959.

COMITÊ GESTOR DA INTERNET NO BRASIL - CGI.br. Banda Larga no Brasil: um estudo sobre a evolução do acesso e da qualidade das conexões à Internet. Cadernos NIC.br - Estudos Setoriais. São Paulo: NIC.br, 2018. 
DAOUD, A. A., Alanyali, M., Starobinski, D. Secondary pricing of spectrum in cellular CDMA networks, in: Proceedings of IEEE DySPAN, April, 2007.

EISENHARDT, K.Agency theory. An assessment and review. Academy of Management Review, 14, pp. 57-74, 1989.

ELECTRONIC COMMUNICATIONS COMMITTEE -ECC. ECC Report 205. Disponível em: http://www.erodocdb.dk/Docs/doc98/ official/pdf/ECCREP205.PDF.

FEDERAL COMMUNICATIONS COMMISSION - FCC. Promoting Efficient Use of Spectrum Through Elimination of Barriers to the Development of Secondary Markets. Notice of proposed rulemaking (FCC 00-402). Washington: FCC, 2000.

. The FCC's 5G FAST Plan. Office of Chairman Pai. Washington: FCC, 2018.

. Notice of Proposed Rulemaking FCC n 19-22, distribuído em 15 de março de 2019. Disponível em: https://docs.fcc.gov/public/attachments/FCC-19-22A1.pdf.

. Policy Statement in the Matter of Principles for Promoting the Efficient Use of Spectrum by Encoraging the Development of Secondary Markets. Washington: FCC, 2000.

FREYENS, B. P. Shared or exclusive radio waves? A dilemma gone astray. Telematics and Informatics 27, p. 293-304, 2009.

JENSEN, M., MECKLING, W. Theory of the firm: managerial behavior, agency costs, and ownership structure. Journal of Financial Economics, 3, pp. 305-360, 1976.

LYONS, D. Secondary markets can pave the way for rapid 5G deployment. American Enterprise Institute. AEIdeas, march 21, 2019. Disponivel em https://www.aei.org/technology-andinnovation/telecommunications/secondary-markets-can-pave-the-wayfor-rapid-5g-deployment/.

MYERSON, R. SATTERTHWAITE, M. Efficient mechanisms for bilateral trading. Journal of Economic Theory 28, pp. 265-281, 1983.

NERA Economic Consulting. 5G spectrum auctions alternatives in Latin America and the Caribbean. New York: NERA, 2019. 
ORGANIZAÇÃO PARA A COOPERAÇÃO E DESENVOLVIMENTO ECONÔMICO-OECD. Secondary Markets for Spectrum: Policy Issues. OECD Digital Economy Papers, $n^{0}$ 95, 2005, OECD Publishing, Paris. http://dx.doi.org/10.1787/232354100386.

ORGANIZAÇÃO PARA A COOPERAÇÃO E DESENVOLVIMENTO ECONÔMICO-OECD/INTER-AMERICAN DEVELOPMENT BANK IDB. Broadband Policies for Latin America and the Caribbean: A Digital Economy Toolkit. Paris: OECD Publishing, http://dx.doi.org/10.1787/9789264251823-en.

SPILLER, P., CARDILLI, C.G. Towards a property rights approach to communications spectrum. Yale Journal on Regulation 16 (1), p. 53-83, 1999.

THE OFFICE OF COMMUNICATIONS - OFCOM. Award of the $700 \mathbf{~ M H z}$ and 3.6-3.8 GHz spectrum bands. London: OFCOM, 2019.

VALLETTI, T.M. Spectrum trading. Telecommunications Policy, v. 25, p. 655-670, 2001.

XAVIER, P., YPSILANTI, D. Policy issues in spectrum trading. INFO, v. 8(2), p. 34-61, 2006. 